\title{
Effect of diet on fatty acid compositions in Sciaenops ocellatus
}

\author{
J. P. Turner* And J. R. RoOKer \\ Texas A\&M University at Galveston, Department of Marine Biology, Galveston, \\ TX 77551, U.S.A.
}

(Received 16 April 2004, Accepted 26 April 2005)

\begin{abstract}
The role of dietary polyunsaturated fatty acids (PUFAs) on the fatty acid composition of juvenile red drum Sciaenops ocellatus was investigated. Individuals $(n=435)$ were fed three natural diets (Gulf menhaden Brevoortia patronus, brown shrimp Farfantapenaeus aztecus and Atlantic brief squid Lolliguncula brevis) that had significantly different proximate composition, energy density and PUFA compositions for 40 days. Diets were characterized as containing: high lipid, high protein, high energy and low PUFA (fish-based), low lipid, low protein, low energy, moderate PUFA (shrimp-based), and low lipid, high protein, moderate energy and high PUFA levels (squid-based), respectively. Specimens were collected at days 0 , $5,10,20$ and 40 to evaluate rate of dietary fatty acid composition in tissues. Two-source mixing models were used to calculate dietary fatty acid accumulation in consumer tissues. Results indicated that juvenile red drum incorporated an average of $35 \%$ dietary PUFAs after 5 days. Although relative biomass and dietary proximate composition had an effect upon the dietary fatty acid contribution, red drum averaged $91 \%$ incorporation of the five most prevalent PUFAs $[18: 2(n-6), 20: 4(n-6), 20: 5(n-3), 22: 5(n-3)$ and $22: 6(n-3)]$ across all diets after 40 days. Growth varied as a function of diet and rates were higher for individuals fed the squid diet than those fed shrimp or fish diets primarily due to increased levels of protein and PUFAs [including $22: 6(n-3) ; 25.8 \%$ ] in the diet. Red drum fed squid exhibited the greatest increase in average dietary fatty acid contribution by day 5 , a trend that continued for the duration of the experiment. Since PUFA composition in red drum was significantly influenced by diet in as few as 5 days and almost completely incorporated into body tissues after 40 days, results from this study support the premise that fatty acids (especially PUFAs) are promising dietary indicators and may be useful for future studies examining trophic relationships of estuarine and marine fishes.

(C) 2005 The Fisheries Society of the British Isles
\end{abstract}

Key words: fatty acids; proximate composition; PUFAs; red drum; Sciaenops ocellatus.

\section{INTRODUCTION}

Due to the central ecological role of fishes as consumers, an understanding of trophic structure of aquatic ecosystems is often essential to ecological studies and to fishery assessment and management. Identification of trophic pathways

*Author to whom correspondence should be addressed at present address: University of New Orleans, Department of Biology, New Orleans, LA 70148, U.S.A. Tel.: +1 504280 1055; fax: +1 5042807483 ; email: jpturnel@uno.edu 
requires a detailed understanding of dietary histories and such information is needed to determine relationships among individuals, populations and communities within the aquatic environment (Hanson \& Chouinard, 2002; Jennings et al., 2002). In the past, dietary histories have been reconstructed using techniques involving direct observations or some measure of ingestion, including scat or stomach contents analysis (Brule \& Rodriguez Canche, 1993). Due to inherent problems associated with conventional measures of diet (e.g. gut content analysis), however, considerable effort has been afforded to the development of alternative approaches (e.g. fatty acids and stable isotopes) to identify trophic links and determine food web structure within marine systems (Fry \& Sherr, 1988; Iverson, 1993).

Fatty acids comprise major components of most lipid classes and are especially common in nearly all marine organisms. Most fatty acids $>18$ carbons in length are transferred into a consumer's tissues with little or no alteration from diet (Iverson, 1993; Iverson et al., 1997). Polyunsaturated fatty acids (PUFAs), fatty acids containing more than one double bond, are a prevalent substance in marine organisms and are typically the most abundant and highly conserved fatty acids in the marine environment (Watanabe, 1993; Sargent et al., 1995; Gurr et al., 2002). In recent years, fatty acids have been increasingly used as natural tracers of diet for a variety of marine organisms including invertebrates, fishes, sea turtles and marine mammals (Ackman et al., 1972; Fraser et al., 1989; Graeve et al., 1994; Iverson et al., 1997; Kirsch et al., 1998). Studies using fatty acids as dietary indicators typically focus on PUFAs since they cannot be synthesized de novo, are rarely modified by marine fishes, are essential for life processes and are therefore the optimal choice in delineating feeding pathways (Raclot et al., 1998; Hastings et al., 2001; Graeve et al., 2002; Gurr et al., 2002). The inability to synthesize PUFAs in fishes is thought to be due to a relaxation of constrains on biochemical pathways, specifically elongase and desaturase enzymes (Hastings et al., 2001). Comparatively, most saturated and monounsaturated fatty acids can be produced endogenously. For example, conversion of saturated fatty acids into monounsaturates has been shown in several marine fishes, including red drum Sciaenops ocellatus (L.) (Lochmann \& Gatlin, 1993a, $b$; Ibeas et al., 1996; Hastings et al., 2001). The ability to modify monounsaturates into PUFAs, or modify PUFAs into longer and further desaturated fatty acids, however, has been lost or severely limited in marine fishes (Hastings et al., 2001).

Modification of fatty acid profiles in the tissues of cultured fish species have been studied extensively (Mourente et al., 1993; Castell et al., 1994; Ibeas et al., 1996; Sargent et al., 1997; Tucker et al., 1997), however, the purpose of such studies often involve the alteration of tissue composition to increase the growth, survival or marketability of cultured species. Although previous studies attempting to quantify PUFA transfer in marine consumers have suggested that diet influences PUFAs in consumer tissues (Fraser et al., 1989; Kirsch et al., 1998), they failed to examine the extent of dietary PUFA incorporation into consumer tissues. Therefore, even though studies are increasingly using fatty acids as biomarkers for investigating trophic interactions in marine ecosystems, basic experiments quantifying dietary PUFA transfer in estuarine and marine fishes have yet to be completed. 
In this study, the effect of dietary PUFAs upon the composition of consumer tissue was determined for an estuarine-dependent fish, the juvenile red drum. Because fatty acid composition of the experimental diets was unique and distinct from the diet individuals were initially reared on, fatty acid composition and deposition rates could be evaluated. Specific objectives of the present study were to quantify the timing and extent of dietary fatty acid incorporation in tissues of captive raised red drum fed diets of significantly different fatty acid and proximate composition. The effects of varying dietary fatty acid and proximate composition on growth, biomass and lipid levels in juvenile red drum were also assessed.

\section{MATERIALS AND METHODS}

\section{FISH REARING AND SAMPLING}

Juvenile (30 day old) red drum were obtained from Sea Center Texas, a fish hatchery in Freeport, Texas, U.S.A., that produces juvenile red drum for releasing into Texas bays for stock enhancement as part of the Texas Parks and Wildlife Department (TPWD) stocking programme. Red drum were spawned in May 2000, and reared in $1233.5 \mathrm{~m}^{3}$ ponds, and fed a variety of locally available microfauna. Specimens were collected prior to release and therefore all individuals met with health and condition criteria for TPWD fingerlings. The experiment was preformed at the Texas A\&M Mariculture Facility on the campus of Texas A\&M University at Galveston, U.S.A., where individuals were acclimated for $24 \mathrm{~h}$ in a single 1441 tank. An initial sample of red drum $(n=35)$ was taken prior to starting the experiment to obtain baseline values for total length $\left(L_{\mathrm{T}}\right)$, mass, proximate composition and fatty acid composition. Test red drum $(n=400)$ were then randomly caught by dipnet and stocked (44-45 fish per tank) into nine circular, 1441 tanks, with flow-through, aerated, filtered sea water. Individuals were fed one of three diets: Gulf menhaden Brevoortia patronus Goode, brown shrimp Farfantapenaeus aztecus or Atlantic brief squid Lolliguncula brevis. All diet species were collected from Galveston Bay, Texas, U.S.A., during the same 7 day period. Specimens were ground frozen with hand-held Braun mixers, freeze-dried for $24 \mathrm{~h}$, and then ground a second time into fine particulate. Red drum were fed treatment diets at 5-7\% of their body mass per day for 40 days. Three replicate tanks were used for each diet, and all tanks were maintained at $24^{\circ} \mathrm{C}$ for the duration of the experiment. Eight-red drum were randomly sampled from each tank at 5,10,20 and 40 days and daily feeding rations were modified according to mass gain. Individual fish were measured for $L_{\mathrm{T}}(\mathrm{mm})$, blotted dry, weighed $( \pm 0.001 \mathrm{~g})$, placed in high-density polyethylene bags, and frozen at $-30^{\circ} \mathrm{C}$. Temperature, salinity and dissolved oxygen levels were measured in all tanks on a daily basis. A $12 \mathrm{~L}: 12 \mathrm{D}$ photoperiod was utilized throughout the study. Salinity ranged between 35 and 38 (mean \pm S.D., 36.19 $\pm 0 \cdot 44$ ); temperature ranged between 23 and $26^{\circ} \mathrm{C}$ (mean \pm S.D., $24 \cdot 21 \pm 0 \cdot 46^{\circ} \mathrm{C}$ ); dissolved oxygen ranged between $7 \cdot 0$ and $8 \cdot 1 \mathrm{mg} 1$ ${ }_{-1}$ (mean \pm S.D., $7 \cdot 1 \pm 0 \cdot 3 \mathrm{mg}^{-1}$ ). ANOVA identified no tank effects for salinity $(P=0 \cdot 168)$, temperature $(P=0 \cdot 868)$ or dissolved oxygen $(P=0 \cdot 211)$.

\section{PROXIMATE COMPOSITION}

Proximate composition analysis (lipid, protein, ash and water) was conducted on the three diets, while only lipid and water contents were assessed in red drum due to lack of sample mass. Two replicate diet samples were taken for each analysis and averaged while red drum were analysed individually. Samples were freeze-dried in a Labconoco lyophilizer for $24 \mathrm{~h}$ to determine water content. Total lipid was then quantified through petroleum ether extraction in a Soxhlet extractor for $24 \mathrm{~h}$ (Dobush et al., 1985). Samples of lean dried material were then incinerated in a muffle furnace for $12 \mathrm{~h}$ at 
$550^{\circ} \mathrm{C}$ to determine ash and ash-free dry lean mass $\left(M_{\mathrm{AFDL}}\right)$. The $M_{\mathrm{AFDL}}$ was composed of 94\% protein and is typically a good estimate of protein composition (Montevecchi et al., 1984). Carbohydrate content was assumed to be negligible in red drum and not analysed in the present study. Calculations of energy density $\left(\mathrm{kJ} \mathrm{g}^{-1}\right)$ and energy content $\left(\mathrm{kJ}_{\text {individual }}{ }^{-1}\right)$ from proximate composition were conducted using standardized published energy equivalents (lipid $=39 \cdot 3 \mathrm{~kJ} \mathrm{~g}^{-1}$ and protein $=17 \cdot 8 \mathrm{~kJ} \mathrm{~g}^{-1}$; Schmidt-Nielsen, 1997).

\section{GROWTH}

Gross lipid content and the amount of individual fatty acids were expressed as a function of relative biomass to asses the effects of changes in lipid and fatty acid composition of tissues $\left(M_{\mathrm{R}}\right), M_{\mathrm{R}}=M_{t} M_{i}^{-1}$, where $M_{t}$ is the mass of an individual at time $t$ and $M_{i}$ is the mass of an individual at the start of the feeding trial.

\section{FATTY ACIDS}

Lipid from individual red drum and the three experimental diets were extracted in duplicate aliquots using techniques from Folch et al. (1957) as modified by Iverson et al. (2001). Gross lipid content of individuals was expressed as an average of two replicates. Fatty acid methyl esters (FAME) were prepared directly from $100 \mathrm{mg}$ of pure extracted lipid (filtered and dried over anhydrous sulphate), using Hilditch procedures (Iverson et al., 1992). FAME analysis was run in duplicate using temperature-programmed gas chromatography according to Iverson (1993) on a Perkin Elmer Autosystem II Capillary FID gas chromatograph fitted with a $30 \mathrm{~m} \times 0.25 \mathrm{~mm}$ internal diameter column coated with $50 \%$ cyanopropyl polysilohexane $(0 \cdot 25 \mu \mathrm{m}$ film thickness; J\&W DB-23; Folsom, CA, U.S.A.) and linked to a computerized integration system (Turbochrome 4 software, Perkin Elmer) (Iverson et al., 1997). After injection at $153^{\circ} \mathrm{C}$ the oven temperature was increased to $174^{\circ} \mathrm{C}$ at a rate of $2 \cdot 3^{\circ} \mathrm{C} \mathrm{min}{ }^{-1}$, then to $220^{\circ} \mathrm{C}$ at $2 \cdot 5^{\circ} \mathrm{C} \mathrm{min}{ }^{-1}$, and finally held constant for $3 \mathrm{~min}$. Identification of fatty acids and isomers was determined from known standards (Nu Check Prep., Elysian, MN, U.S.A.). Individual fatty acids were converted to mass per cent of total fatty acids using conversion factors from Ackman $(1972,1991)$.

\section{DATA ANALYSIS}

ANOVA was used to determine tank effects for temperature, salinity and dissolved oxygen. Multivariate analysis of variance (MANOVA), ANOVA and Tukey's honestly significant difference (HSD $\alpha=0 \cdot 05$ ) tests were used to investigate differences in PUFA composition of the three experimental diets, and the PUFA composition in individuals from replicate tanks. Principal components analysis (PCA) was used to explore the multivariate relationship among diets and red drum collected at various times throughout the experiment using multiple PUFAs as variables. Factors were extracted using a correlation matrix with minimum eigenvalues of $1 \cdot 0$. Normality and homogeneity of variances were verified using Kolmogorov-Smirnov and Bartlett tests, respectively. Fatty acid data were arcsine-transformed before ANOVA were run to correct for their binomial distribution (percentages) (Zar, 1998). Statistical tests were preformed with statistical packages SPSS 8.0 (SPSS Inc. Chicago, IL, U.S.A.).

Two-source mixing models are commonly utilized to determine contribution from two potential prey sources (prey a and prey b) to a predator (Vander Zanden \& Rasmussen, $2001)$. In the present study mixing models were used to determine fatty acid contribution $(F ; \%)$ from two dietary sources (diet a and diet b) to a red drum (fish): $F_{\text {diet a }}=100$ $\left(F_{\text {fish }}-F_{\text {diet b }}\right)\left(F_{\text {diet a }}-F_{\text {diet b }}\right)^{-1}$ and $F_{\text {diet b }}=100-F_{\text {diet a }}$, where diet a represents the initial $F$ values in (day 0 ) red drum, diet b represents the $F$ values for each experimental diet, and fish represents the $F$ values in red drum at each stage of the experiment. 


\section{RESULTS}

\section{DIETS}

Lipid, AFDLM, ash and energy density differed significantly among the three diets (Table I; ANOVA, $P<0 \cdot 001$ ). Lipid composition was significantly higher in the fish-based diet than either of the diets $(P<0 \cdot 001)$. The $M_{\mathrm{AFDL}}$ was significantly lower in the shrimp-based diet than the fish-based diet $(P<0 \cdot 001)$ or squidbased diet $(P=0 \cdot 003)$, while levels of ash were significantly lower in the squidbased diet than either of the other diets $(P<0 \cdot 001)$. Energy densities of the three diets were significantly different from each other $(P<0 \cdot 001)$. Proximate composition of the three diets can be summarized as containing on a relative basis: high lipid, high protein and high energy (fish-based), low lipid, low protein and low energy (shrimp-based), and low lipid, high protein and moderate energy levels (squid-based).

\section{GROWTH}

Thirty day-old red drum (referred to as day 0 red drum or red drum at the start of trial) ranged between 20 and $35 \mathrm{~mm} L_{\mathrm{T}}$ (mean \pm s.D., $28 \pm 3.5 \mathrm{~mm}$ ) and between 0.069 and $0.348 \mathrm{~g}$ in mass (mean \pm s.D., $0 \cdot 183 \pm 0.065 \mathrm{~g}$ ). Growth rate varied significantly by date of collection and diet. Significant differences in $L_{\mathrm{T}}$ and mass were observed among the three diets by day 10, and this trend continued through to day 40. Specifically, red drum fed the squid-based diet were significantly larger and heavier than individuals fed the other two diets throughout the remainder of the study (ANOVA, $P<0 \cdot 001$ ). Red drum fed the squid-based diet doubled their relative biomass $\left(M_{\mathrm{R}}=2\right)$ at a significantly greater rate than individuals fed fish-based or shrimp-based diets (Fig. 1; $P<0 \cdot 001)$. Biomass of red drum fed the squid-based diet increased two-fold within $c .8$ days, whereas red drum fed fish-based or shrimp-based diets did not double in biomass until 18 and 20 days, respectively. Red drum fed the squidbased diet had significantly higher $M_{\mathrm{R}}$ values than the other diets at days 10-40 $(P<0 \cdot 001)$; no significant differences in $M_{\mathrm{R}}$ were detected between red drum fed fish-based and shrimp-based diets $(P=0 \cdot 210)$.

\section{GROSS LIPID COMPOSITION}

Gross lipid content in juvenile red drum reflected dietary composition, decreasing in red drum fed shrimp-based and squid-based diets while increasing in individuals fed a fish-based diet (Tables II, III and IV). Differences in lipid content $(\%)$ between individuals collected on day 0 and day 40 and among day 40 red drum were significant for all three diets (ANOVA, $P<0 \cdot 001$ ). Red drum fed the two low-lipid diets (shrimp-based and squid-based) exhibited dietary lipid contributions of $78 \cdot 3$ and $97 \cdot 3 \%$, respectively, compared with only $27 \cdot 1 \%$ in the high-lipid (fish-based) diet. Low dietary contribution of lipid in individuals fed the fish-based diet is probably due to the extreme differences in per cent lipid composition between day 0 red drum and the fish-based diet as compared with moderate differences between day 0 individuals and both shrimp-based and 


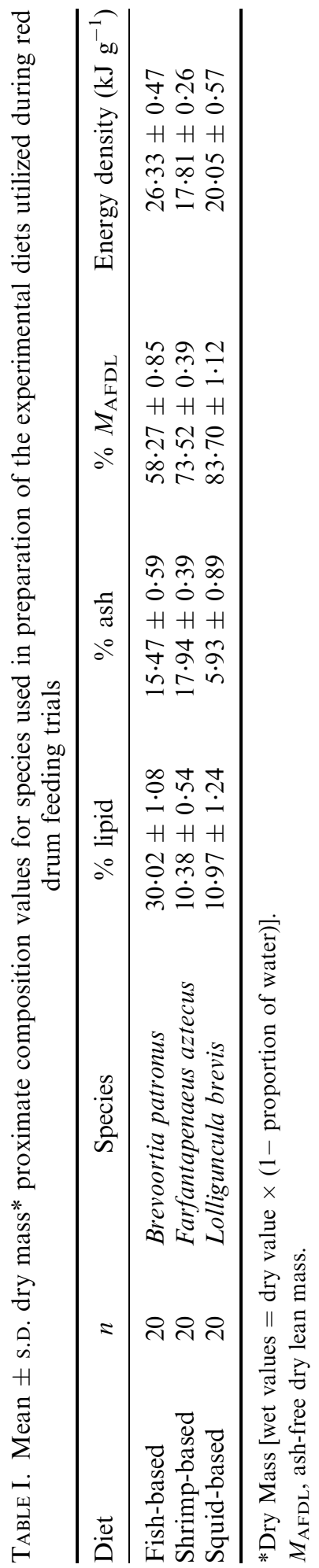




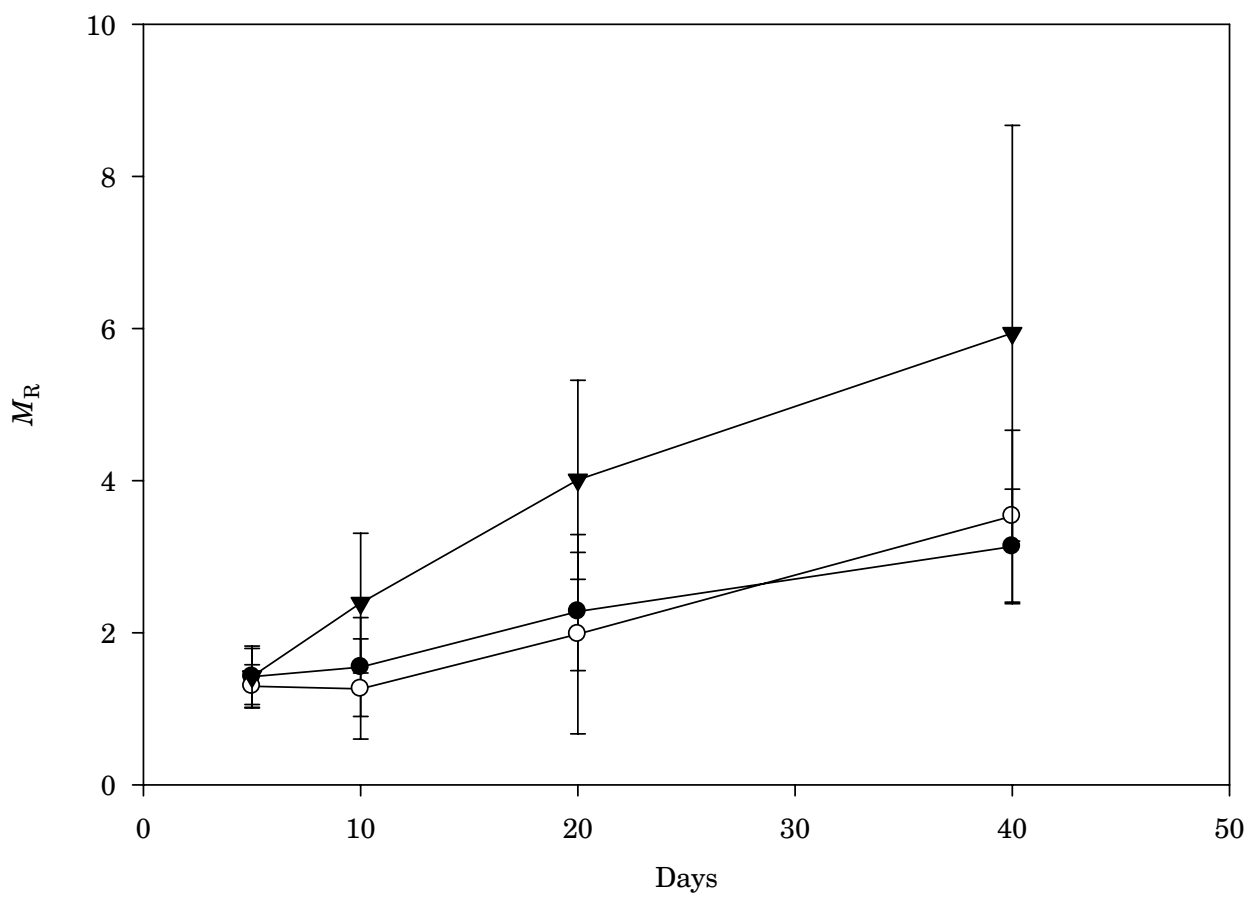

FIG. 1. Mean \pm S.D. relative biomass increase of red drum fed fish- $(\bullet)$, shrimp- $(\bigcirc)$ and squid-based $(\boldsymbol{\nabla})$ diets over a 40 day period.

squid-based diets (Tables II, III and IV). Per cent lipid composition was expressed as a function of $M_{\mathrm{R}}$ for red drum fed each of the three diets. A positive relationship was identified between lipid percentage and relative biomass increase for individuals fed the fish-based diet [Fig. 2(a); slope $=0.5829$, $P<0.001]$, while negative relationships were documented in red drum fed both the shrimp-based [Fig. 2(b); slope $=-0 \cdot 1878, P=0.025]$ and squidbased [Fig. 2(c); slope $=-0 \cdot 1886, P<0 \cdot 001]$ diets.

\section{FATTY ACIDS}

Sixty-seven individual fatty acids were identified during analysis. Analysis was limited to PUFAs and further to two subsets based upon per cent amount. A group of 18 PUFAs (referred to as 'all PUFAs') represented those with values $>0 \cdot 5 \%$ (Tables II, III and IV) while a group of the five most abundant PUFAs (referred to as '5 PUFAs') was also utilized. Although not utilized for analysis, total per cent saturated, monounsaturated and PUFAs were calculated and reported (Tables II, III and IV). The five PUFAs $18: 2(n-6)$ (linoleic), $20: 4(n-6)$ (arachidonic, AA), $20: 5(n-3)$ (eicosapentaenoic, EPA), $22: 5(n-3)$ (docosapentaenoic) and $22: 6(n-3)$ (docosa- hexaenoic acid, DHA) were used throughout most analyses due to their high abundance in red drum and diets $(23 \cdot 8-34 \cdot 4 \%$ of the PUFAs and $19 \cdot 6-50 \cdot 1 \%$ of the total fatty acids) and to reduce the number of variables in analyses. Further reference to 'PUFA compositions' is based upon these five abundant PUFAs. 


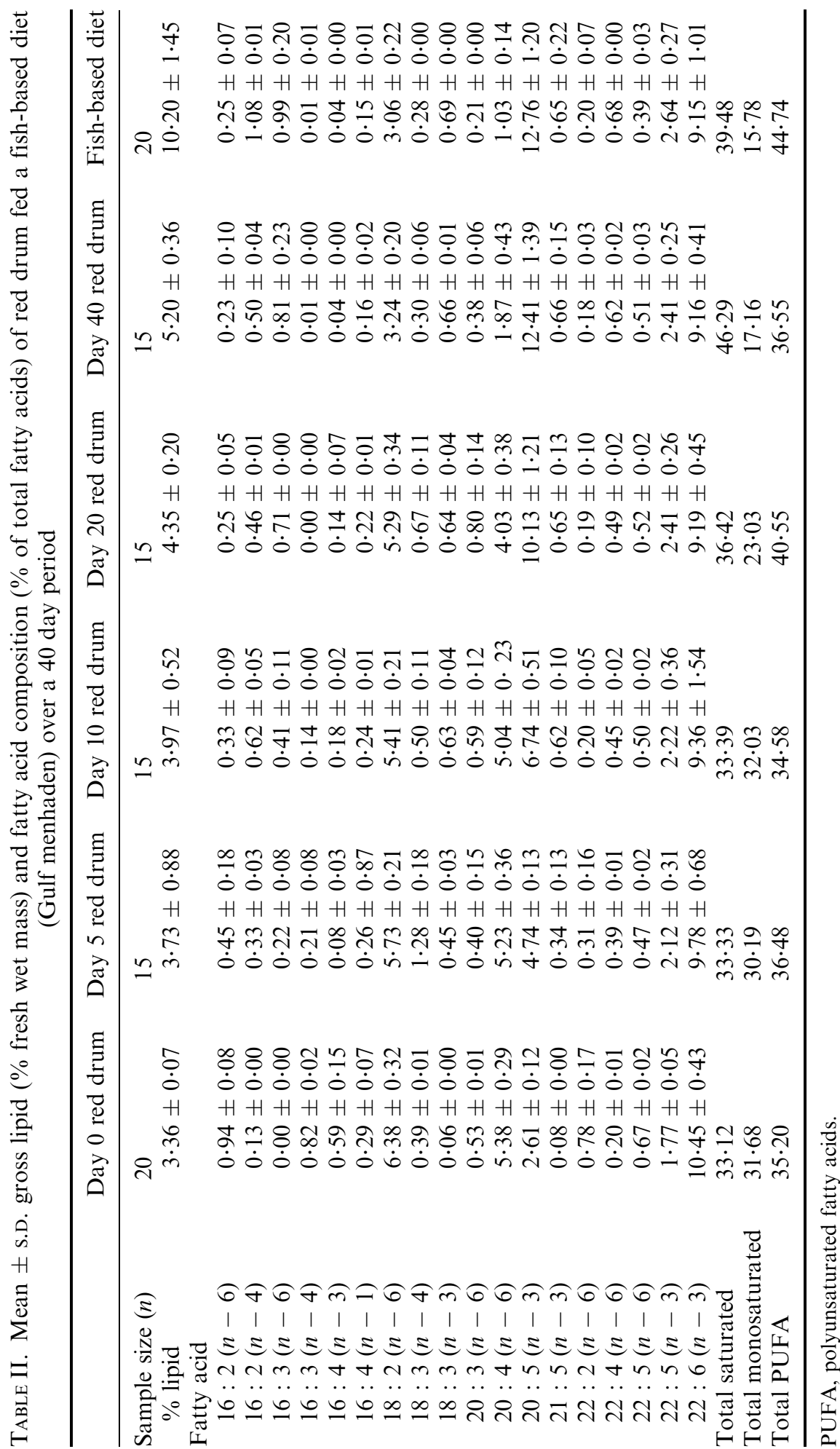




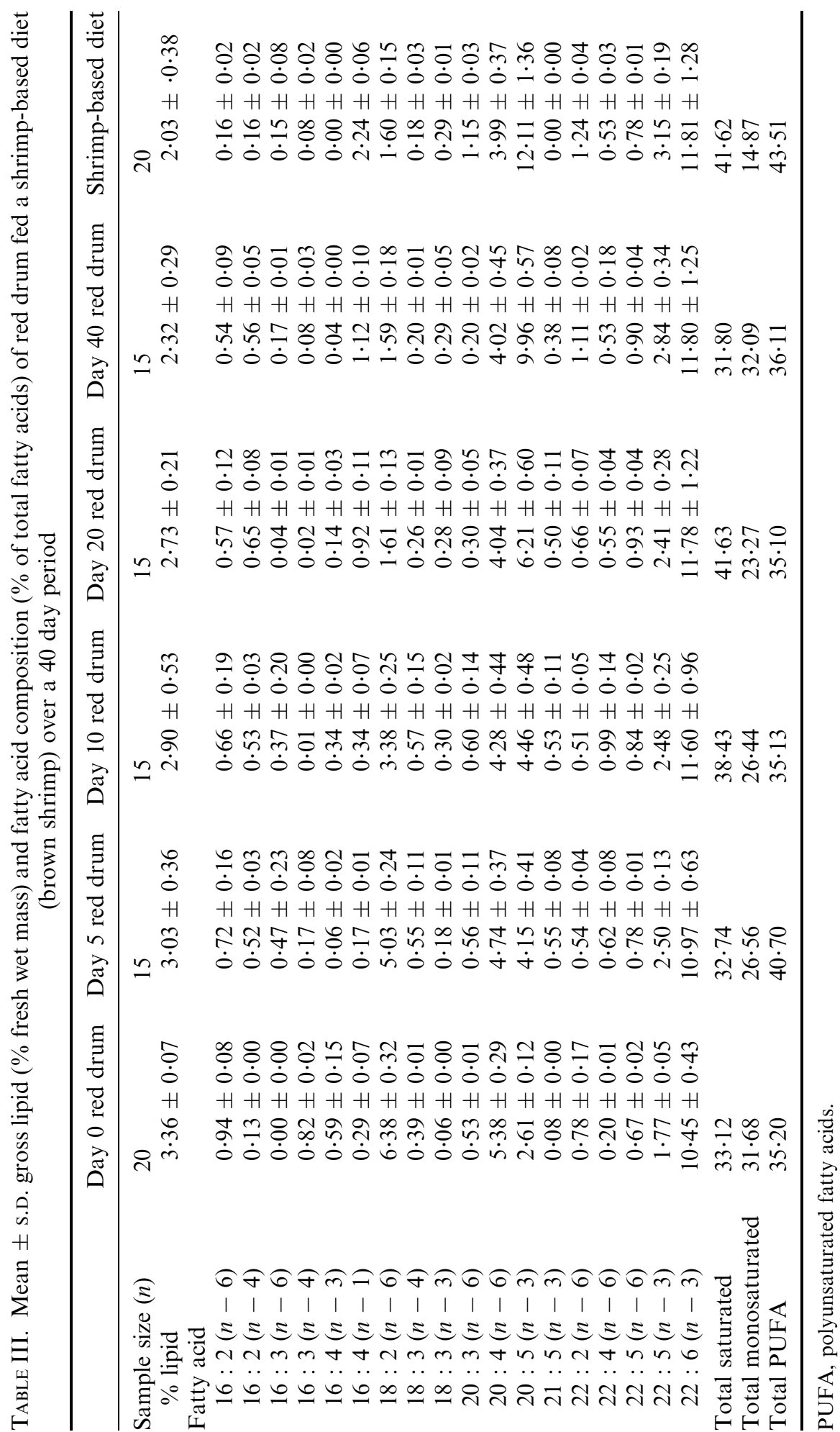




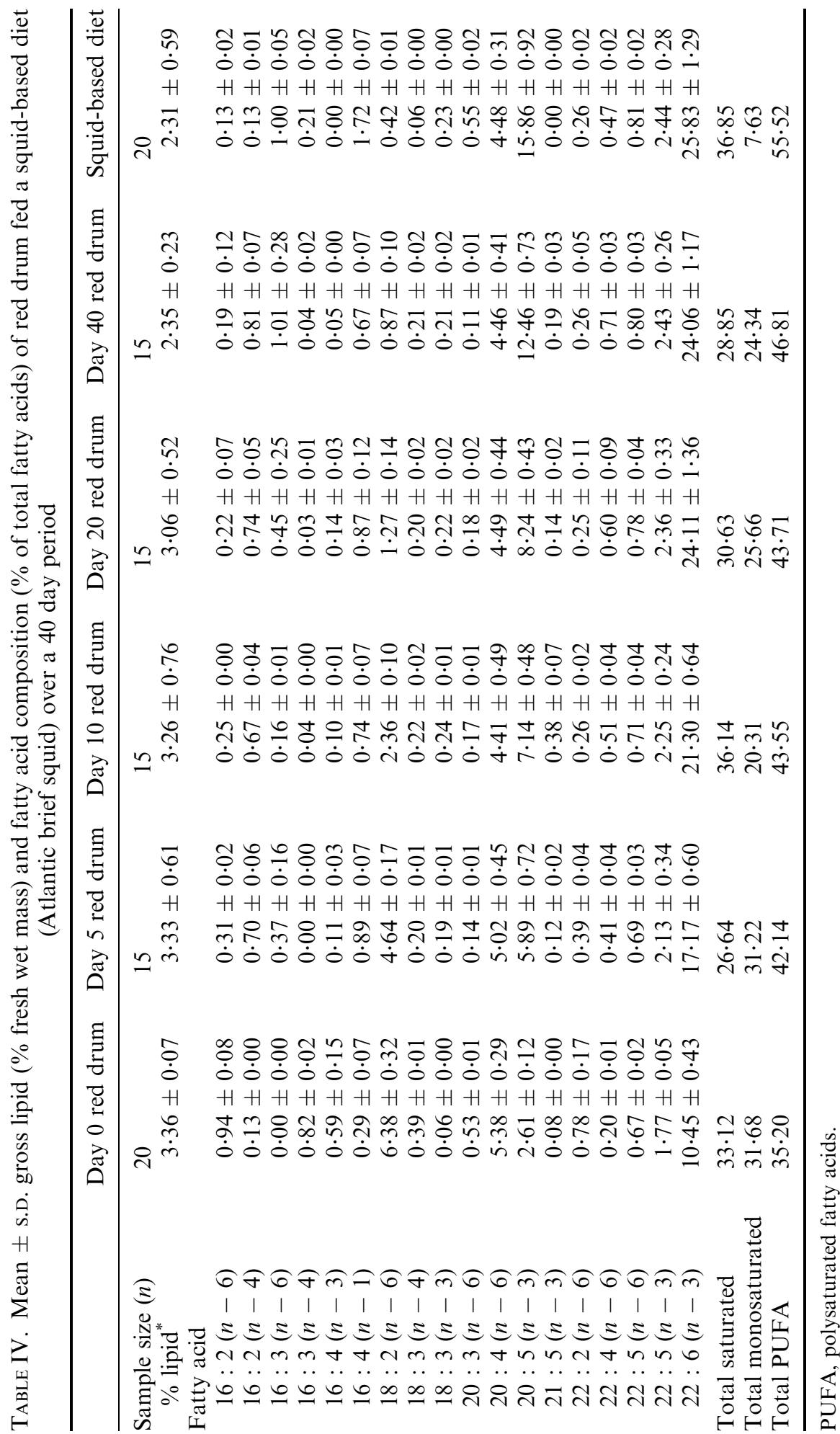



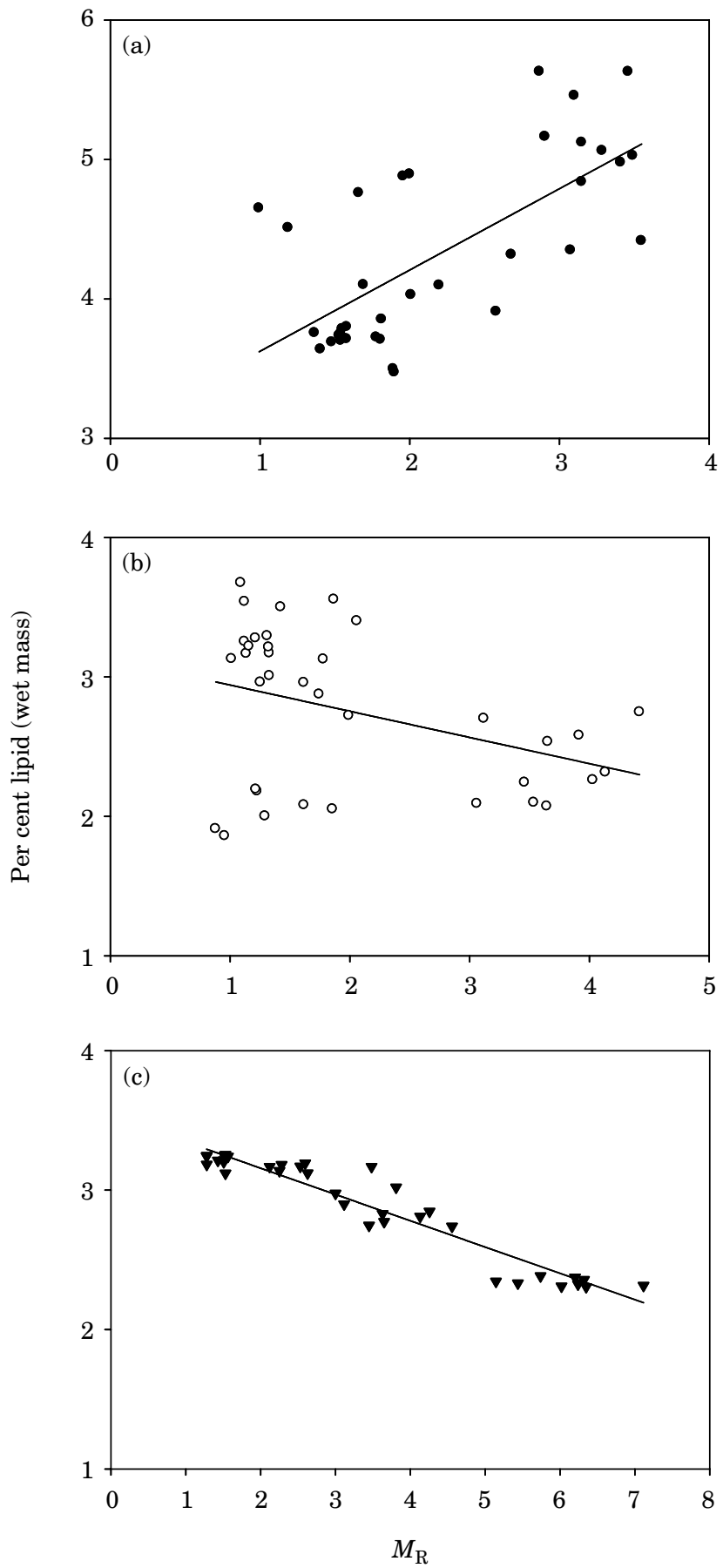

FIG. 2. Regression plot of per cent lipid (wet mass) composition on relative biomass for red drum fed (a) fish- (•), (b) shrimp- $(\bigcirc)$ and (c) squid-based $(\boldsymbol{\nabla})$ diet. 
No significant differences in individual PUFAs were detected among red drum from replicate tanks (MANOVA) for each of the four dietary treatments: fishbased $\left(F_{10,130}, P=0 \cdot 516\right)$, shrimp-based $\left(F_{12,124}, P=0 \cdot 355\right)$ and squid-based $\left(F_{12,120}, P=0 \cdot 589\right)$. Red drum collected before the change in diet were characterized by low levels of $20: 5(n-3)$ and $22: 5(n-3)$, and $22: 5(n-6)$ $(2 \cdot 6 \%$ and $1 \cdot 8 \%$, respectively) and high levels of $18: 2(n-6), 20: 4(n-6)$, and $22: 6(n-3)(6 \cdot 4 \%, 5 \cdot 4 \%$, and $10 \cdot 5 \%$, respectively). Individuals fed different diets acquired significantly different PUFA compositions throughout the study (MANOVA, $F_{10,382}, P<0 \cdot 001$ ). Univariate tests (ANOVA) indicated that after the change, significant differences were identified in all individual PUFAs among diets $(P<0 \cdot 05)$. Subsequently, red drum fed the fish-based diet contained significantly higher levels of $20: 5(n-3)$ and $22: 5(n-3)$, individuals fed the shrimp-based diet contained significantly higher levels of $20: 5(n-3)$, $22: 5(n-3)$ and $22: 6(n-3)$, while juveniles fed the squid-based diet contained significantly higher levels of $20: 5(n-3), 22: 5(n-3)$ and $22: 6(n-3)$.

Mixing models were used to calculate fatty acid contribution from each experimental diet using the five PUFAs. Rates of dietary contribution of these five PUFAs from each diet were significantly different (MANOVA, $F_{12,366}$, $P<0.001)$. Red drum fed the squid-based diet showed the largest increase in average dietary fatty acid contribution by day 5 at $40.9 \%$, while individuals fed the shrimp-based and fish-based diets exhibited $36 \cdot 3$ and $26 \cdot 6 \%$ respectively. This trend continued at each stage of the experiment. At days 10, 20 and 40 red drum fed the squid-based diet contained an average of $79 \cdot 6,91 \cdot 4$ and $96 \cdot 4 \%$ fatty acid dietary contribution, respectively [Fig. 3(a)]. During the same period, individuals fed the shrimp-based diet averaged 59.5, 78.6 and 90.4\% and those fed fish-based diet averaged $42 \cdot 7,61 \cdot 7$ and $88 \cdot 9 \%$, respectively [Fig. 3(b), (c)].

Levels of PUFAs in individual red drum were closely related to levels found in each respective diet by day 40 of the experiment. PCA was performed using all PUFAs and the five prevalent PUFAs values for red drum collected at days 0,5 , 10, 20 and 40, along with each diet. Over $86 \cdot 1 \%$ of the variation in composition of the five prevalent PUFA could be explained by principal components 1 and 2 while only $64.4 \%$ could be explained using all PUFA. Scatterplots of components 1 and 2 revealed a larger degree of similarity among individual red drum and their respective diet using the five prevalent compared with all PUFA as the experiment progressed [Fig. 4(a), (b)].

\section{DISCUSSION}

In the present study, the extent of dietary contribution in each individual PUFA (5 PUFAs) sampled [18: $2(n-6), 20: 4(n-6), 20: 5(n-3), 22: 5$ $(n-3)$, and $22: 6(n-3)]$ in juvenile red drum was considerable, averaging of $27-41 \%$ after 5 days and $>91 \%$ after 40 days, indicating that dietary PUFAs were very suggestive of recent dietary changes. It appears red drum acquire most $n-3$ and $n-6$ series PUFAs [e.g. 20:4 $(n-6), 20: 5(n-3)$ and $22: 6$ $(n-3)$ ] directly from diet since they cannot be synthesized de novo and are necessary for proper development, which is consistent with previous research on marine fishes (Watanabe, 1993; Evjemo et al., 1997; Copeman et al., 2002). Similar findings have been reported in tissues of red drum, as PUFAs (especially 

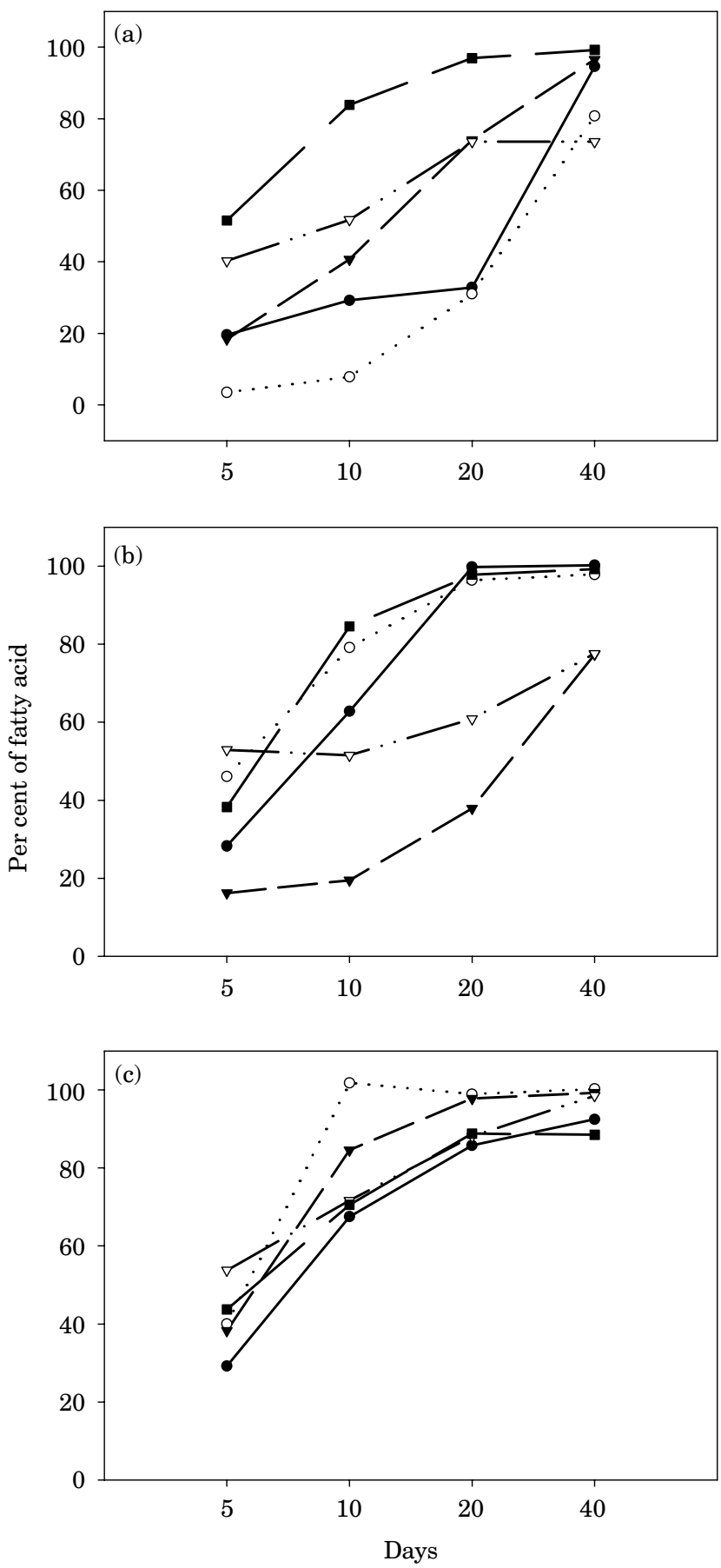

FIG. 3. Mean per cent of five prevalent individual polyunsaturated fatty acids [-๑-, $18: 2(n-6)$; $\cdot \cdot \bigcirc \cdot \cdot, 20: 4(n-6) ;-\nabla-, 20: 5(n-3) ;-\nabla-, 22: 5(n-3) ;-\boldsymbol{\square}-22: 6(n-3)]$ within red drum fed a (a) fish-, (b) shrimp-, -, and (c) squid-based diet. 


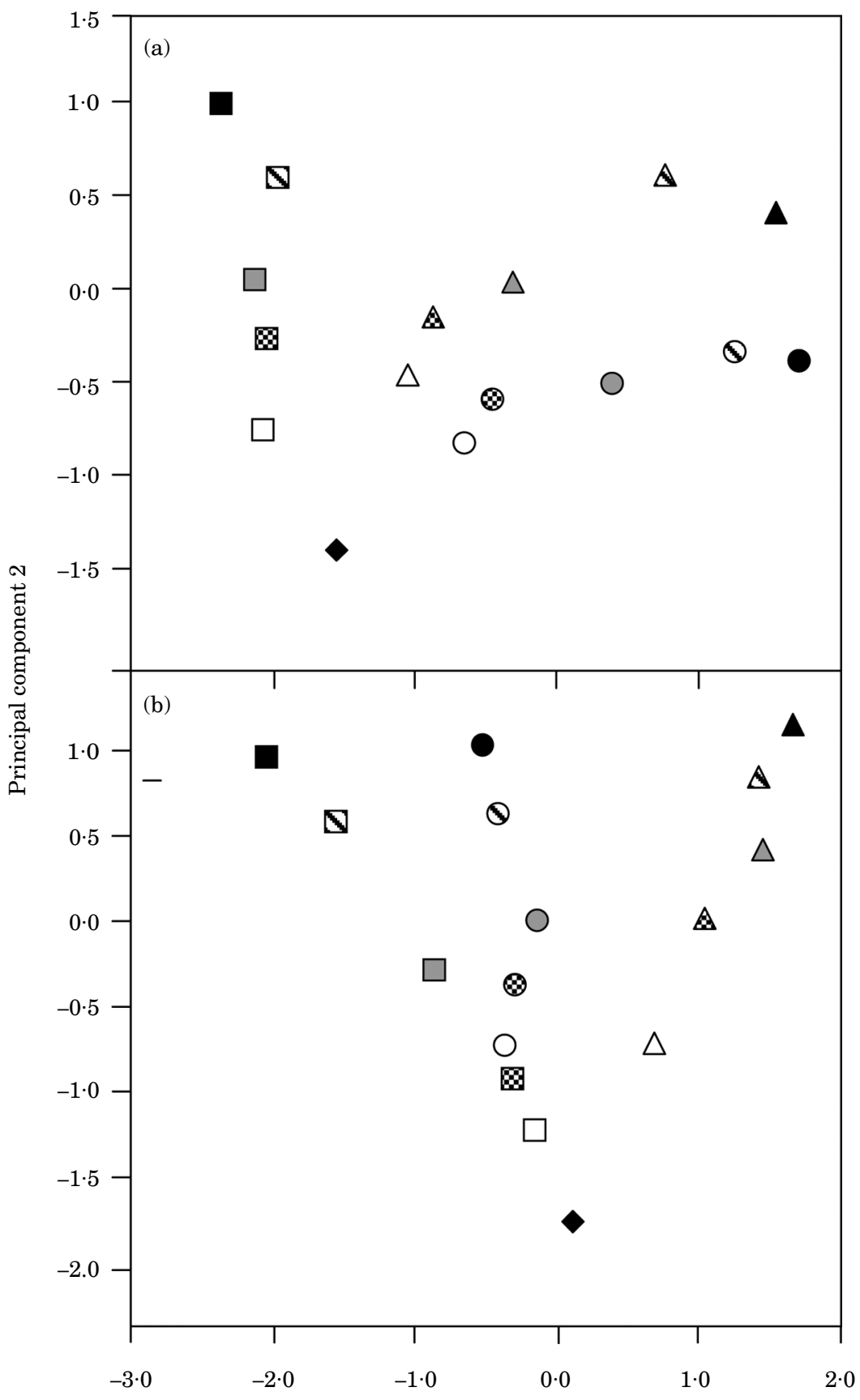

Principal component 1

FIG. 4. Plot of principal components 1 and 2 for (a) 'all' polyunsaturated fatty acids (PUFAs) and (b) five prevalent PUFAs of red drum fed fish- ( $\mathbf{\square})$, shrimp- $(\boldsymbol{\Lambda})$ or squid-based $(\bullet)$ diets and collected on days $0(\diamond), 5(\square), 10(\mathbb{\otimes}), 20(\square)$ and $40(\mathbf{\nabla})$ of the experiment. Values are mean PUFA of red drum for each diet and collection day. 
n-3) are often directly proportional to those found in the diet (Lochmann \& Gatlin, 1993a; Brinkmeyer \& Holt, 1998). Therefore, it appears that like other marine fishes, red drum lack the $\Delta 5$ and $\Delta 6$ desaturases, both of which are required to modify $18: 2(n-6)$ into $20: 4(n-6)$, and $18: 3(n-3)$ into $20: 5(n-3)$ and $22: 6(n-6)$ (Lochmann \& Gatlin, 1993a; Brinkmeyer \& Holt, 1998; Hastings, et al. 2001), demonstrating that these fatty acids may be promising indicators of dietary history.

Although all PUFA levels were linked to diet, individual PUFAs were incorporated into red drum tissue at different rates. Specifically, conservation of $22: 6(n-3)$ was much greater throughout the experiment, averaging $84 \cdot 2 \%$ dietary contribution, compared with $18: 2(n-6)(62 \cdot 0 \%), 20: 4(n-6)(58 \cdot 4 \%), 20: 5(n-3)$ $(57 \cdot 1 \%)$ and $22: 5(n-3)(65 \cdot 3 \%)$. It is well known that long-chain PUFAs of the n-3 series, particularly $22: 6(n-3)$, are essential for marine fishes. Neural tissues (brain and retina) in fishes and higher vertebrates contain disproportionately large amounts of $22: 6(n-3)$, and it may also play specific roles in neural membrane structure and function (Bell \& Dick, 1991; Evjemo et al., 1997). In addition, $22: 6(n-3)$ has been shown to be an important factor in the growth, survival, developmental behaviour and physiological tolerance in marine fishes (Evjemo et al., 1997; Harel et al., 2001; Ishizaki et al., 2001; Copeman et al., 2002). Therefore, large requirements of $22: 6(n-3)$ in larval and juvenile marine fishes could explain an increased proportional conservation of this PUFA compared with other PUFAs in the tissues of juvenile red drum.

As expected, high levels of lipid in the diet of red drum in the present study lead to increased deposition of body lipids. Further, lipid composition of red drum tissues in the present study was reflective of levels present in each experimental diet. Red drum fed the squid-based diet accumulated lipid approximately equal to dietary leve1s, with a per cent dietary contribution of $97 \cdot 3 \%$ by day 40 of the experiment. Although red drum fed the fish-based and shrimp-based diets did not exhibit this level of contribution $(27 \cdot 0$ and $78 \cdot 2 \%$, respectively), lipid deposition still reflected changes in dietary composition. In previous studies of red drum, an increase in fat deposition is typically shown in response to elevated dietary lipids (Ellis \& Reigh, 1991; Lochmann \& Gatlin, 1993a; Craig \& Gatlin, 1995; Craig et al., 1999; Davis et al., 1999). Similar effects have also been noted in other marine fishes (Kennish et al., 1992; Nematipour et al., 1992; Fair et al., 1993; Kirsch et al., 1998), indicating that red drum, like other marine fishes, respond to increased dietary lipid levels by increasing deposition rates.

Dietary levels of PUFAs were positively correlated with growth of red drum in the present study, indicating that the retrospective turnover rates of the five most prevalent PUFAs was a function of relative biomass. Red drum fed the squidbased diet doubled their biomass at a significantly greater rate than individuals fed either the fish-based or shrimp-based diets. From days 10-40, red drum fed the squid-based diet exhibited a biomass increase nearly two times that of individuals fed the other two diets. Typically, an increase in dietary protein and energy levels can have a positive effect upon growth rates and nutrient retention. An increase in muscle and skeletal mass (protein and ash) is often considered to be true growth while lipid deposition is primarily energy storage (Tucker et al., 1997). Thus, a diet rich in protein and essential lipid components (PUFAs) should lead to relatively constant growth, although the ratio of lipid 
gain to protein gain would be affected by both endogenous and exogenous factors, including diet. In the present study the squid-based diet contained significantly more protein and PUFAs than either the fish-based or shrimp-based diet, and since protein growth is directly related to protein consumed (McCarthy et al., 1994; Mommsen, 1998), it is not surprising that red drum fed the squid-based diet exhibited a proportionally higher growth rate than individuals raised on diets with less protein. In addition, studies on red drum have demonstrated that dietary PUFAs are linked to somatic growth (Craig et al., 1994; Lochman \& Gatlin, $1993 a$, $b$; Brinkmeyer \& Holt, 1995). Average levels of the five PUFAs in this study were significantly greater in red drum fed the squid-based diet than individuals fed the other two diets between days 10 and 40, and turnover rates of individual PUFAs were dependent upon rate of biomass increase and time. At a relative biomass increase of two, red drum fed the shrimp-based diet exhibited the greatest turnover in three of the five PUFAs. By the time red drum fed the shrimpbased diet had reached a relative biomass increase of two, however, individuals fed the squid-based diet had quadrupled biomass. Since dietary PUFA requirements must be met for optimum growth to occur in marine fishes (Watanabe, 1982; Greene \& Selivonchick, 1987), observed growth rates of red drum may be a function of both high protein and elevated levels of PUFAs.

Results of PCA show that tissues of juvenile red drum reflect the fatty acid composition of their recent diet in a predictable manner and therefore could be used to retrospectively determine recent dietary history in 'wild' estuarine and marine fishes. Variations in PUFA compositions of the diets used in the present study represent natural differences found in prey species throughout estuarine ecosystems. Studies in feeding ecology have used such variability to identify habitat utilization by larval and juvenile fishes using similar techniques (Deegan, 1990; Herzka \& Holt, 2000). For example, Herzka \& Holt (2000) were able to determine the timing of dietary shift at settlement as well as habitat utilization of post-settlement red drum larvae by comparing changes in carbon and nitrogen stable isotopes with age. Since red drum in the present study reflected fatty acid composition of recent diets, newly settled 'wild' juveniles should reflect the composition of prey in each specific habitat and movement patterns of individuals could be characterized by tracking fatty acid prey 'signatures' from different habitats. Further, high levels of PUFAs (especially n-3) have been positively correlated with growth and reproductive success in marine fauna, leading to an increase in fecundity, egg hatchability, along with growth and survival in larvae and juveniles (Leonardos \& Lucas, 2000; Wen et al., 2002). Limited availability of n-3 PUFAs in estuarine and marine habitats have led to significant reductions in fecundity and hatchability of individual species and have enormous potential to limit production in estuarine and marine food webs (Hazzard \& Kleppel, 2003). Thus, fatty acids used to investigate patterns of habitat use may yield further significant information relating to the potential growth, survival and quality of habitat in settling individuals, and potentially develop into a valuable tool for examining trophic relationships among estuarine and marine communities and delineating nutritional production in aquatic food webs. Precaution must be exercised, however, when using the technique since additional work must be completed to fully understand the effects of ontogeny on PUFA transfer and incorporation. 
The present results suggest that PUFAs are reflective of diet in red drum and may be useful as dietary markers in field applications. The five most prevalent PUFAs [18:2 $(n-6), 20: 4(n-6), 20: 5(n-3), 22: 5(n-3)$ and $22: 6$ $(n-3)]$ were representative of diet and found in large concentrations within tissues of red drum, and significant dietary contribution of fatty acids occurred in as few as 5 days. Moreover, $89-96 \%$ of dietary fatty acids were incorporated into the tissues of red drum by day 40 of the experiment. Proximate and fatty acid composition of diet had significant effects on growth of red drum, and high dietary levels of protein and PUFAs produced the highest growth rates. As expected, high levels of lipid in the diet of red drum in the present study lead to increased deposition of body lipids. Results of this study indicate that PUFAs in the tissue of red drum can be used to track feeding history and may be useful for retrospectively examining trophic relationships of estuarine and marine fishes in aquatic systems.

The authors would like to thank two anonymous reviewers for helpful comments and suggestions with this paper. The manuscript greatly benefited from helpful comments by D. Gatlin, S. Smith and G.A.J. Worthy. The present study was funded by the Aquarium at Moody Gardens, Galveston, Texas. Juvenile Redfish were provided by Sea Center Texas fish hatchery in Freeport, Texas. S.J. Iverson, H.R. Smith and G.A.J. Worthy provided assistance with fatty acid analysis.

\section{References}

Ackman, R. G. (1972). The analysis of fatty acids and related materials by gas-liquid chromatography. In Progress in the Chemistry of Fats and Other Lipids, Vol. 12 (Holman, R. T., ed.), pp. 165-284. Oxford: Pergamon Press.

Ackman, R. G. (1991). Application of gas-liquid chromatography to lipid separation and analysis: qualitative and quantitative analysis. In Analyses of Fats, Oils and Lipoproteins (Perkins, E. G., ed.), pp. 270-300. Champaign, IL: American Oil Chemists Society.

Ackman, R. G., Hooper, S. N. \& Sipos, J. C. (1972). Distribution of trans-6hexadecenoic and other fatty acids in tissues and organs of the Atlantic leatherback turtle, Dermochelys coriacea coriacea. International Journal of Biochemistry 3, 171-179.

Bell, M. V. \& Dick, J. R. (1991). Molecular species composition of the major diacylglycerophospholipids from muscle, liver, retina, and brain of cod (Gadus morhua). Lipids 26, 565-573.

Brinkmeyer, R. L. \& Holt, G. J. (1995). Response of red drum larvae to graded levels of menhaden oil in semipurified microparticulate diets. Progressive Fish-Culturist 57, 30-36.

Brinkmeyer, R. L. \& Holt, G. J. (1998). Highly saturated fatty acids in diets for red drum (Sciaenops ocellatus) larvae. Aquaculture 161, 253-267.

Brule, T. \& Rodriguez Canche, L. G. (1993). Food habits of juvenile red groupers, Epinephelus morio (Valenciennes, 1828), from Campeche Bank, Yucatan, Mexico. Bulletin of Marine Science 52, 772-779.

Castell, J. D., Bell, J. G., Tocher, D. R. \& Sargeant, J. R. (1994). Effects of purified diets containing different combinations of arachidonic and docosahexaenoic acid on survival, growth, and fatty acid composition of juvenile turbot (Scophthalmus maximus). Aquaculture 128, 315-333.

Copeman, L. A., Parrish, C. C., Brown, J. A. \& Harel, M. (2002). Effects of docosahexaenoic, eicosapentaenoic, and arachidonic acids on the early growth, 
survival, lipid composition and pigmentation of yellowtail flounder (Limanda ferruginea): a live food enrichment experiment. Aquaculture 210, 285-304.

Craig, S. R. \& Gatlin, D. M. III (1995). Coconut oil and beef tallow, but not tricaprylin, can replace menhaden oil in the diet of red drum (Sciaenops ocellatus) without adversely affecting growth or fatty acid composition. Journal of Nutrition 125, 3041-3048.

Craig, S. R., Arnold, C. R. \& Holt, G. J. (1994). The effects of enriching live foods with highly unsaturated fatty acids on the growth and fatty acid composition of larval red drum Sciaenops ocellatus. Journal of the World Aquaculture Society 25, 424-431.

Craig, S. R., Washburn, B. S. \& Gatlin, D. M. III (1999). Effects of dietary lipids on body composition and liver function in juvenile red drum, Sciaenops ocellatus. Fish Physiology and Biochemistry 21, 249-255.

Davis, D. A., Lazo, J. P. \& Arnold, C. R. (1999). Response of juvenile red drum (Sciaenops ocellatus) to practical diets supplemented with medium chain triglycerides. Fish Physiology and Biochemistry 21, 235-247.

Deegan, L. A. (1990). Effects of estuarine environmental conditions on population dynamics of young-of-the-year gulf menhaden. Marine Ecology Progress Series 68, 195-205.

Dobush, G. R., Ankney, C. D. \& Krementz, D. G. (1985). The effect of apparatus, extraction time, and solvent type on lipid extractions of snow geese. Canadian Journal of Zoology 63, 1917-1920.

Ellis, S. C. \& Reigh, R. C. (1991). Effects of dietary lipid and carbohydrate levels on growth and body composition of juvenile red drum, Sciaenops ocellatus. Aquaculture 97, 383-394.

Evjemo, J. O., Coutteau, P., Olsen, Y. \& Sorgeloos, P. (1997). The stability of docosahexaenoic acid in two Artemia species following enrichment and subsequent starvation. Aquaculture 155, 135-148.

Fair, P. H., Williams, W. P. \& Smith, T. I. J. (1993). Effect of dietary menhaden oil on growth and muscle fatty acid composition of hybrid striped bass, Morone chrysops $\times$ M. saxatilis. Aquaculture 116, 171-189.

Folch, J., Lees, M. \& Sloan-Stanley, G. H. (1957). A simple method for the isolation and purification of total lipides from animal tissues. Journal of Biological Chemistry 226, 497-509.

Fraser, A. J., Sargent, J. R., Gamble, J. C. \& Seaton, D. D. (1989). Formation and transfer of fatty acids in an enclosed marine food chain comprising phytoplankton, zooplankton, and herring (Clupea harengus L.) larvae. Marine Chemistry 27, 1-18.

Fry, B. \& Sherr, E. B. (1988). $\delta^{13}$ C measurements as indicators of carbon flow in marine and freshwater ecosystems. In Stable Isotopes in Ecological Research (Rundel, P. W., Ehleringer, J. R. \& Nagy, K. A., eds), pp. 196-229. New York: Springer-Verlag.

Graeve, M., Kattner, G. \& Hagen, W. (1994). Diet-induced changes in fatty acid composition of Arctic herbivorous copepods: experimental evidence of trophic markers. Journal of Experimental Marine Biology and Ecology 182, 97-110.

Graeve, M., Kattner, G., Wiencke, C. \& Karsten, U. (2002). Fatty acid composition of Arctic and Antarctic macroalgae: indicator of phylogenetic and trophic relationships. Marine Ecology Progress Series 231, 67-74.

Greene, D. H. S. \& Selivonchick, D. P. (1987). Lipid metabolism in fish. Progress in Lipid Research 26, 53-85.

Gurr, M. I., Harwood, J. L. \& Frayn, K. N. (2002). Lipid Biochemistry; 5th edn. Malden, MA: Blackwell Science.

Hanson, J. M. \& Chouinard G. A. (2002). Diet of Atlantic cod in the southern Gulf of St Lawrence as an index of ecosystem change, 1959-2000. Journal of Fish Biology 60, 902-922. doi: 10.1006/jfbi.2002.1893

Harel, M., Gavasso, S., Leshin, J., Gubernatis, A. \& Place, A. R. (2001). The effect of tissue docosahexaenoic acid levels on hypersaline tolerance and leucocyte 
composition in striped bass (Morone saxatilis) larvae. Fish Physiology and Biochemistry 24, 113-123.

Hastings, N., Agaba, M., Tocher, D. R., Leaver, M. L., Dick, J. R., Sargent, J. R. \& Teale, A. J. (2001). A vertebrate fatty acid desaturase with $\Delta 5$ and $\Delta 6$ activities. Proceedings of the National Academy of Sciences USA 98, 14304-14309.

Hazzard, S. E. \& Kleppel, G. S. (2003). Egg production of the copepod Acartia tonsa in Florida Bay: role of fatty acids in the nutritional composition of the food environment. Marine Ecology Progress Series 252, 199-206.

Herzka, S. Z. \& Holt G. J. (2000). Changes in isotopic composition of red drum (Sciaenops ocellatus) larvae in response to dietary shifts: potential applications to settlement studies. Canadian Journal of Fisheries and Aquatic Sciences 57, 137-147.

Ibeas, C., Cejas, J., Gomez, T., Jerez, S. \& Lorenzo, A. (1996). Influence of dietary n-3 highly unsaturated fatty acids levels on juvenile gilthead seabream (Sparus aurata) growth and tissue fatty acid composition. Aquaculture 142, 221-235.

Ishizaki, Y., Masuda, R., Uematsu, K., Shimizu, K., Arimoto, M. \& Takeuchi, T. (2001). The effect of dietary docosahexaenoic acid on schooling behaviour and brain development in larval yellowtail. Journal of Fish Biology 58, 1691-1703. doi: 10.1006/jfbi.2001.1579

Iverson, S. J. (1993). Milk secretion in marine mammals: can milk fatty acids predict diet. Symposium. Zoological Society of London 66, 263-291.

Iverson, S. J., Sampugna, J. \& Oftedal, O. T. (1992). Positional specificity of gastric hydrolysis of long-chain $n-3$ polyunsaturated fatty acids of seal milk triglycerides. Lipids 27, 870-878.

Iverson, S. J., Frost, K. J. \& Lowry, L. F. (1997). Fatty acid compositions reveal fine scale structure of foraging distribution of harbor seals and their prey in Prince William Sound, Alaska. Marine Ecology Progress Series 151, 255-271.

Iverson, S. J., Lang, S. \& Cooper, M. (2001). Comparison of the Bligh and Dyer and Folch methods for total lipid determination in a broad range of marine tissue. Lipids 36, 1283-1287.

Jennings, J., Pinnegar, J. K., Polunin, N. V. C., \& Warr, K. J. (2002). Linking size-based and trophic analyses of benthic community structure. Marine Ecology Progress Series 226, 77-85.

Kennish, J. M., Sharp-Dahl, J. L., Chambers, K. A., Thrower, F. \& Rice, S. D. (1992). The effect of a herring diet on lipid composition, fatty acid composition, and cholesterol levels in the muscle tissue of pen-reared Chinook salmon (Oncorhynchus tshawytscha). Aquaculture 108, 309-322.

Kirsch, P. E., Iverson, S. J., Bowen, W. D., Kerr, S. R. \& Ackman, R. G. (1998). Dietary effects on the fatty acid signature of whole Atlantic cod (Gadus morhua). Canadian Journal of Fisheries and Aquatic Sciences 55, 1378-1386.

Leonardos, N. \& Lucas, I. A. N. (2000). The use of larval fatty acids as an index of growth in Mytilus edulis L. larvae. Aquaculture 184, 155-166.

Lochmann, R. T. \& Gatlin, D. M. III (1993a). Essential fatty acid requirement of juvenile red drum (Sciaenops ocellatus). Fish Physiology and Biochemistry 12, 221-235.

Lochmann, R. T. \& Gatlin, D. M. III (1993b). Evaluation of different types and levels of triglycerides, singly and in combination with different levels of $n-3$ highly unsaturated fatty acid ethyl esters in diets of juvenile red drum, Sciaenops ocellatus. Aquaculture 114, 113-130.

McCarthy, I. D., Houlihan, D. F. \& Carter, C. G. (1994). Individual variation in protein turnover and growth efficiency in rainbow trout, Oncorhynchus mykiss (Walbaum). Proceedings of the Royal Society of London B 257, 141-147.

Mommsen, T. P. (1998). Growth and metabolism. In The Physiology of Fishes, $2^{\text {nd }}$ edn (Evans, D. H., ed.), pp. 65-97. Boca Raton, FL: CRC Press.

Montevecchi, W. A., Ricklefs, R. E., Kirkham, I. R. \& Gabaldon, D. (1984). Growth energetics of nestling gannets (Sula bassanus). Auk 101, 334-341.

Mourente, G., Rodriguez, A., Tocher, D. R. \& Sargent J. R. (1993). Effects of dietary docosahexaenoic acid (DHA; 22:6n-3) on lipid and fatty acid compositions and 
growth in gilthead sea bream (Sparus aurata L.) larvae during first feeding. Aquaculture 112, 79-98.

Nematipour, G. M., Brown, M. L. \& Gatlin, D. M. III (1992). Effects of dietary carbohydrate:lipid ratio on growth and body composition of hybrid striped bass. Journal of the World Aquaculture Society 23, 128-132.

Raclot, T., Groscolas, R. \& Cherel, Y. (1998). Fatty acid evidence for the importance of myctophid fishes in the diet of king penguins, Aptenodytes patagonicus. Marine Biology 32, 523-533.

Sargent, J. R., Bell, J. G., Bell, M. V., Henderson, R. J. \& Tocher, D. R. (1995). Requirement criteria for essential fatty acids. Journal of Applied Ichthyology 11, 183-198.

Sargent, J. R., McEvoy, L. A. \& Bell, J. G. (1997). Requirements, presentation and sources of polyunsaturated fatty acids in marine fish larval feeds. Aquaculture 155, $119-129$.

Schmidt-Nielsen, K. (1997). Animal Physiology: Adaptation and Environment, 5th edn. New York: Cambridge University Press.

Tucker, J. W. Jr, Lellis, W. A., Vermeer, G. K., Roberts, D. E. Jr \& Woodward, P. N. (1997). The effects of experimental starter diets with different levels of soybean or menhaden oil on red drum (Sciaenops ocellatus). Aquaculture 149, 323-339.

Vander Zanden, M. J. \& Rasmussen, J. B. (2001). Variation in $\delta^{15} \mathrm{~N}$ and $\delta^{13} \mathrm{C}$ trophic fractionation: Implications for aquatic food webs. Limnology and Oceanography 46, 2061-2066.

Watanabe, T. (1982). Lipid nutrition in fish. Comparative Biochemistry and Physiology B 73, $3-15$.

Watanabe, T. (1993). Importance of docosahexaenoic acid in marine fish larvae. Journal of the World Aquaculture Society 24, 152-161.

Wen, X. B., Chen, L. Q., Zhou, Z. L., Ai, C. X., \& Deng, G. Y. (2002). Reproduction response of Chinese mitten-handed crab (Eriocheir sinensis) fed different sources of dietary lipid. Comparative Biochemistry and Physiology A 131, 675-681.

Zar, J. H. (1998). Biostatistical Analysis, 4th edn. New Jersey: Prentice Hall. 